\title{
Approach to a Logistic Model to Reduce Costs for Delivery at Home of a Seller of Supplies in Times of Coronavirus
}

Hernán Washington Samaniego Guevara*

Logistics and Supply Chain, Popular Autonomous University of the state of Puebla (UPAEP) and Business Administration, Salesian Polytechnic University, Quito, Av. October 12th 23-52, Ecuador

\author{
A R T I C L E I N F O \\ Article history: \\ Received: 19 August, 2020 \\ Accepted: 13 October, 2020 \\ Online: 26 October, 2020
}

Keywords:

Logistic

Savings method

Cost

Interactions

Routes

\begin{abstract}
A B S T R A C T
Logistics is a science and art that has been widely used by large commercial chains, whose main objectives focus on the distribution of products or services. This understanding has generated various logistics studies directed towards those businesses, without considering that science can also be applied to small or medium enterprises.

The present study initially executes a bibliographic review of multiple works done by several authors that confirm that studies related to the field of logistics can be aimed at any organization. The theoretical investigation of this study is therefore widely supported.

This work is focused on helping a small enterprise continue offering its services during the pandemic caused by the worldwide presence of COVID-19. Hence, the purpose of this research is to present a logistics model that will allow a small supermarket to continue its commercial activities in Quito, Ecuador, in compliance with diverse regulations issued by the Ecuadorian Government. The logistical model uses the methodology called savings method developed by Clarke and Wright.

The designed model produces as a main outcome the establishment of short-distance home delivery routes of provision to customers by the supermarket, thereby achieving significant savings in time and money. Additionally, the design and implementation of the model can serve as an example to be replicated in similar businesses.
\end{abstract}

\section{Introduction}

The logistics service well thought out is vital for the survival of a small, medium, or large enterprise. On many occasions, logistics has been visualized as the last link of the delivery of any product or service. Generally, it is the client who must go to a store to use a particular service or purchase a good [1].

However, this thought necessarily had to be reconsidered due to a worldwide health problem, which required looking at businesses from another perspective, forcing companies to modify their ways of doing businesses. Otherwise, they ran the risk of being pushed out of the market from not adapting to the policies issued by the local and national governments which affect the inhabitants of the city of Quito, Ecuador.

For this reason, a small supply chain has had to adapt to the policies and conditions issued by these organizations, which state

${ }^{*}$ Corresponding Author: Hernán Washington Samaniego Guevara, Email: hernanwashington.samaniego@upaep.edu.mx that the enterprise could work only by home delivery while the government prohibits on-site service at their facilities. Therefore, in accordance with mandated policies, a logistics model was designed for home delivery by looking for a way to reach customers at minimal cost and adapting the enterprise's activities to an integration process necessary for its commercial survival [2].

With these considerations, the supermarket object of study could choose to halt its activities and possibly resume them when the health situation caused by the pandemic has finished, or continue working while adapting them to the state's policies [3]. These realities demonstrated the need to find a solution by characterizing and identifying the logistical management of the provision of the supermarket services in its work context in Quito, Ecuador. The study, carried out with the support of the business owner, has the following objectives: highlighting the logistical routes applicable for this business-type, based primarily on innovation; and the work-family subsistence of those who are involved directly in these activities [4]. 
This study is organized into several sections that present the bibliographic review, the methodology applied, the results achieved, and finally, the conclusions based on the total research carried out.

\section{Literature review}

Logistics in business is a novelty derived from the concept that it adds value to essential products or services for customer satisfaction and sales [5]. Conversely, for other authors, by citing the American Production and Inventory Control Society (APICS), the term logistics is considered the art and science of obtaining, manufacturing and distributing material and products at a place and in adequate quantities [6]. Therefore, logistics can be considered a science that combines the art of satisfying clients at the moment and placetheydesire.

Logistics is big business in the United States of America. In that country, it represents 8 to $9 \%$ of the Gross Domestic Product (GDP), and this percentage is growing [6]. In Europe, the logistics sector in 2018 represented 8\% GDP in most of the countries from the European Union [7].

The use of logistics in any production or service chain is always going to be related to its costs. For example, in the United States, Japan, and Europe, the logistics costs represent under 10\% GDP, while in Mexico it represents 13.5\% GDP. In India and China it represents $17 \%$ and $22 \%$ GDP, respectively [8]. In general, in the first world countries, it is noticed in efficient use of their transport systems, including maritime systems, while in the third world countries, it is more common to see a high degree of bureaucracy, as well as inefficiency [8].

According to the Inter-American Development Bank (DIB), in Latin America, the inefficiency of supply chains, and logistics performance in particular hinders competitiveness. Currently, logistics costs represent between $18 \%$ and $35 \%$ of final product value, which exceeds the percentage registered by the member countries of the Organization for Economic Cooperation and Development (OECD), which is 8\% [9]. Additionally, the logistics costs in Latin America and the Caribbean are between $50 \%$ and $100 \%$ of those of the countries from the OECD [9].

In Ecuador, specifically in Quito, according to a study done by the Municipality of the Metropolitan District of the city, the costs associated with logistics represent between $50 \%$ and $60 \%$ of the costs incurred by enterprises in production or generation of services [10]. This represents a reasonable limit that halts home delivery in general. Only an approximate percentage of $5 \%$ of organizations provide this kind of service [11]. Under this perspective, it is feasible to establish a logistics model that fits the required conditions, which can be used and applied by the supermarket without generating high costs that would increase substantial economic losses for the business.

The logistics model has been studied based on many aspects, for example, the study made in 2014 [9], in which it is established an analysis of the provision of home health services in the Cauca valley in Colombia [4]. In this research, the authors are focused on showing a diagnosis for the institutions authorized by the Ministry of Health of that country, which objective is to characterize how the home health care providers (HHC) make logistical decisions associated with the service delivery process and identify opportunities for improvement and research. The diagnosis of that model is based on the application of a semistructured survey, which evaluated six work axis and the maturity degree of the service processes, by showing in its results that it is required more integral management with the logistics decisions and supported on the knowledge of the epidemiologic and demographic profile of the population served [4].

In 2018, in Mexico, the logistics related to the means of transportation and local development of an exporting organization of table grape was studied; this study is characterized by determining the critical processes in the enterprise operation by looking for ways to develop management efficiency mechanisms to meet market demands in product delivery times to customers with minimal operation costs, but without establishing a specific model to comply with [12].

In a study, a logistic model is proposed to reduce the costs of the furniture painting sub-process, whose central objective is to minimize reprocessing and reduce its costs. This is achieved by identifying the behavior of the costs incurred in production through the use of tools and techniques that add value to the products and by increasing the profit margin as those tools are used [2].

In 2017, a compilation of logistic models is presented to solve problems related to integration, coordination, sustainability, and mobility that arise in the urban distribution of goods; specifically focused on an update of scientific literature with a subsequent categorization of the models and techniques used so that in the future the solutions presented would be implemented [13]. Another study called personalization degree of logistic services: service and performance priorities is presented. The authors focus their research efforts on analyzing the relationship between the types of logistic services required and the supply chain priorities, generating two hypotheses related to this study, which result in a significant association between the variables studied [14].

Another author conducted a logistics study in small and medium-sized companies in the state of Jalisco-Mexico [15], whose focus is on determining knowledge of the logistical state in the business sector of the area of study, which describes the main problems that affect logistics performance and, therefore, the export efficiency of the state. The obtained results indicate that there is an association between logistics and export business efficiency in the state previously mentioned [15]. Additionally, the executed work describes the logistical problem is in its primary nodes, customs, carriers, and customs agents. Identifying the primary type of problem defined in this study has a cultural nature because work is not done as an integrated system; each node is seen as unique and essential throughout the value chain, 
without understanding that it generates a high cost in the export efficiency of the state [15].

One of the few studies made for small and medium-sized companies (SMEs) in Mexico seeks to strengthen the importance of their competitive position through a conceptual model of logistical management via control of the variables involved [16]. It achieves a conceptual reference for SMEs so that they can reach logistical performance according to their needs by integrating resources, skills, and systems and allowing them to accomplish a competitive advantage regarding other companies [16].

In studies carried out in 2019, other authors analyzed the evaluation of the supply chain by considering the direct relationship between a logistical field and the supply chain, and presenting an evaluation model related to companies of the metalworking sector. The model elaborated comprises five aspects: supply, storage, inventory management, distribution, transportation and/or reverse logistics [17]. These factors include a set of variables that evaluate the planning, execution, measurement, and control of the supply chain management. The conclusion was that in the metalworking sector, due to its sustained growth over time, it is necessary to continuously optimize and improve its processes through permanent monitoring, which facilitates the operational processes that actively contribute to an even more significant growth of this type of organization [17].

The lines above have presented various studies carried out by authors who have executed research work in Latin American countries, who present various scientific analyses related to the logistics field. Logistics, in being a science, can be used anywhere in the world and in any labor field [13]. Ecuador is not exempt from such analyses. The research executed by different authors is mainly focused on theoretical works. Some of them study reverse logistics as a differentiation strategy for dynamic markets, highlighting a qualitative-theoretical, historical-logical, analytical-synthetic, and inductive-deductive approach; they seek in this way to highlight that companies that have applied reverse logistics have improved their competitiveness by reducing costs [18].

Their credibility is reflected in the market due to their efforts to minimize the environmental footprint; concluding that the application of the practices covered by reverse logistics increases the possibilities of differentiation from the competition, since it generates trust and security in consumers [18]. Additionally, other authors present a logistics study in a textile company, analyzing the processes that show the most significant difficulties, in which they focus on the processes of production, logistics, and sales, via the use of documentary tools that identify elements that will allow them to recognize logistical processes for companies in the textile sector that contribute to improving the competitiveness of the sector in general, and present as a result a documentary study that facilitates the improvement of processes through strategic decision making [19].
A similar study to those previously mentioned deals with the evolution of digital information in commercial and integral logistics. The research objective of this work was to review the best catalog for searches, trends, and behavior of scientific production over the years by using web tools such as the Scielo catalog, Scopus, and Redalyc; and by specifying trends through Google Trends and Publish or Perish software, presenting a compendium of relevant logistical studies [20].

A document called Research in Logistics and Transport was elaborated, which was based on comparing Ecuador with other countries from the Andean region (Bolivia, Colombia, and Peru) with regards to studies carried out that concern this topic. The comparison looks at competitive aspects of the countries, and relates each one of the points found as relevant factors to identify which country within the Andean region has the most significant development and research concerning logistics and transport [21].

Logistics can be applied to any labor or scientific field. Thus many people consider it a factor that generates competitive advantage [21]. Under this premise, a study focused on the cosmetics and personal care products industry is analyzed. In that study, the authors present a methodological proposal where they analyze factors and variables that characterize this commercial sector and allow the use of the logistics processes and resources in this type of enterprise by practically and directly explaining how these factors should be used along with their variables [22]. In a different approach, the existing relationship between logistics and the environment was studied through content analysis published with relation to logistical studies and supply chain done between 2005 and 2015, while concluding that it is necessary to design support tools for the inclusion of new processes in logistical issues [23].

The research results of a study that relates supplier management to supply chain management show the proposed model that address an existing relationship between an adequate search of suppliers and a strict control of the supply compliance, by providing vital input to generate efficient strategies in this field, and by collaborating on agreements with the suppliers [24].

Finally, it is useful to address a study that performs a competitive diagnostic of the logistical point of view in the central geographical zone of Ecuador. The authors consider the implementation of integral logistics as a competitive advantage in the current global environment. Moreover, they establish that the management of retail stores contributes to cost-reduction if operations are simplified and information flow is improved [25].

When analyzing each of the works presented by the diverse research to which we refer, a high percentage of conceptual studies based on theories applicable to the logistics field are evidenced. However, they do not specify the concrete application of any methodology that allows companies to make practical decisions in the field. This does not mean there is an inability to apply those studies, rather that they leave open the real possibility of using them in different organizations that require it. Based on 
what was analyzed, the study presented below describes how a small supermarket can avoid stopping the sale of its products to customers that request home delivery, by finding efficient routes through the interpretation of a methodology that allows savings in time and cost.

It is important to note that the model designed was structured for a small supply delivery business which lacks the logistical infrastructure owned by medium and giant supermarket chains. The study generates practical-scientific knowledge that can be replicated by other similar organizational structures.

\section{Methodology}

From the regulations issued by control entities in Ecuador due to the type- 2 coronavirus that causes severe acute respiratory syndrome SARS-CoV-2-COVID-19 [26], the sales percentages, in most business, have decreased significantly. Given this situation, among the decrees issued by the Ecuadorian state, the possibility of executing door-to-door sale of food and supplies made by small supermarkets and/or grocery stores was defined by decree number 1052, issued by the Presidency of the Republic of Ecuador [3]. Hence, the study carried out is focused on establishing a logistical model that prioritizes the delivery of supplies or provisions to residential complexes located in the sector known as La Vicentina, in order for the SME to cover the largest number of clients in unique places.

Faced with the present situation, a model of logistical transportation was designed, by using the savings method authored by Clarke and Wright which has persisted for many years [27].

Clarke and Wright's model has been one of the most implemented algorithms to solve the vehicle route problem method (VRP), and it consists in doing a limited exploration of the search space and giving an acceptable quality solution in a moderate time. The algorithm is developed starting from a solution with two routes $(0, . ., \mathrm{i}, \ldots, 0)$ y $(0, \ldots, \mathrm{j}, \ldots, 0)$, which can be combined by generating a single route $(0, \ldots, \mathrm{i}, \mathrm{j}, \ldots, 0)[28]$.

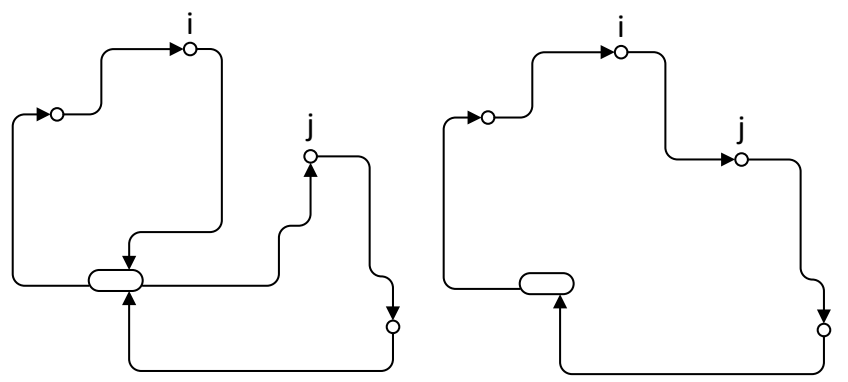

Figure 1: Clarke and Wright's algorithm

Clarke and Wright's method details a very flexible procedure that allows the management of a wide range of practical constraints, and whose resolution on a computer is relatively fast [28]. This method applies to the designed model because the comparisons of the optimal results in small problems, such as in this study case, have shown that the effectiveness of its application generates solutions at $2 \%$ of the optimum on average [5].

The objective of using the savings method is to minimize the total distance covered by the vehicles and indirectly minimize the number of vehicles required to make local stops [5]. The logic of the applied model is mainly based on the fact the small supermarket has only one available vehicle. Therefore, by using Clarke and Wright's algorithm, the mathematical model only considers the existence of a central warehouse as the starting point for all deliveries. The objective function of the proposed model is determined by:

Minimize:

$$
\sum_{i \in V} \sum_{j \in V} \operatorname{CijXij}
$$

The constraints applicable to the proposed model are specified by:

$$
\begin{gathered}
\sum_{i \in V} X i j=1, \quad \forall j \in V \cdot\{0\} \\
\sum_{j \in V} X i j=1, \quad \forall i \in V \cdot\{0\} \\
\sum_{i \in V} X i o=k \\
\sum_{j \in V} X i o=k \\
\sum_{i \nexists S} X i j \geq r(s), \forall S C V \cdot\{0\}, S \neq \emptyset \\
X i j \in\{0,1\}, \forall i, j \in V
\end{gathered}
$$

Constraint number 5 impedes the presence of subtours, where $\mathrm{r}(\mathrm{S})$ is the number of vehicles required to meet the demand in $\mathrm{S}$.

Constraints numbers 5 and 6 have cardinalities that grow exponentially with $\mathrm{n}$, thus, they are replaced with a family of constraints with polynomial cardinality [28]. For the study case, they were set according to the following:

$$
\mathrm{u} i-\mathrm{u} j+\mathrm{Q} i j<=\mathrm{Q}-\mathrm{d} j
$$

Considering that $\mathrm{d} i+\mathrm{d} j<=\mathrm{Q}$

Therefore: $\mathrm{d} i<=\mathrm{u} i<=\mathrm{Q}$

where:

$\mathrm{V}$ : node set $\mathrm{V}=\{\mathrm{V} 0, \mathrm{~V} 1, \mathrm{~V} 2, \ldots . . \mathrm{V} n\}, \mathrm{V} o$ is the warehouse

$A$ : edge set $A=\{(i, j): i, j \in V, i \neq j\}$ 
$\mathrm{d} i$ : node demand $\mathrm{i}$

k: number of available vehicles

Q: vehicle capacity

By mathematically setting the model design, it is possible to verify that its theoretical characteristics are necessary and ideal to establishing a pattern on which the vehicle belonging to the business returns to its facilities only when it has made all the deliveries. The designed model establishes that this delivery is adapted to the needs of the businesses that are the objects of study, and it can be used for a long time [27]. Considering the opinion of an epidemiological expert whose statements say that the SARSCov2 virus will remain for an indefinite time, forcing businesses and people to adapt to living with it, if desired the world economy and its activities to be regularized [29]. In such circumstances, the savings method for the programming and route design is adjusted to the supermarket's needs, by seeking the maximum savings in cost and distances to cover.

Subsequently, and with the theoretical support provided below, with the help of Google Maps, it is possible to visualize the specific places where supplies and provisions are to be delivered, which are identified numerically with small blue circles, as shown in Figure 2.

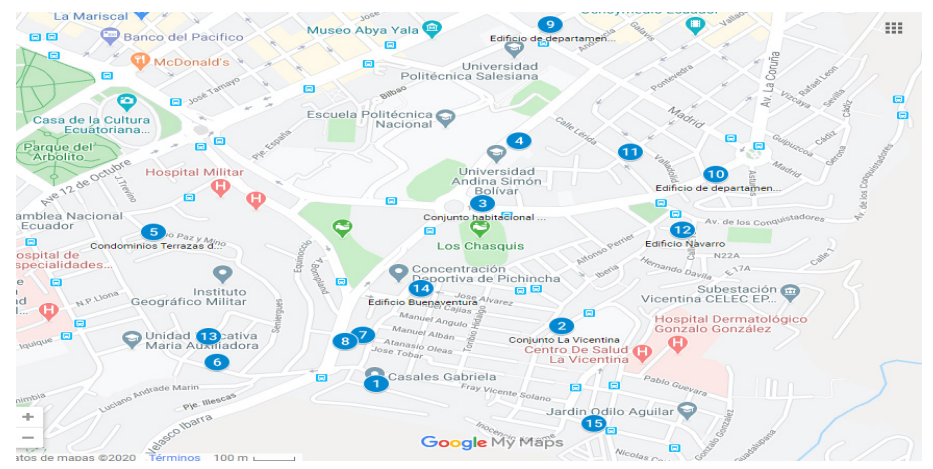

Figure 2: locations of delivery sites

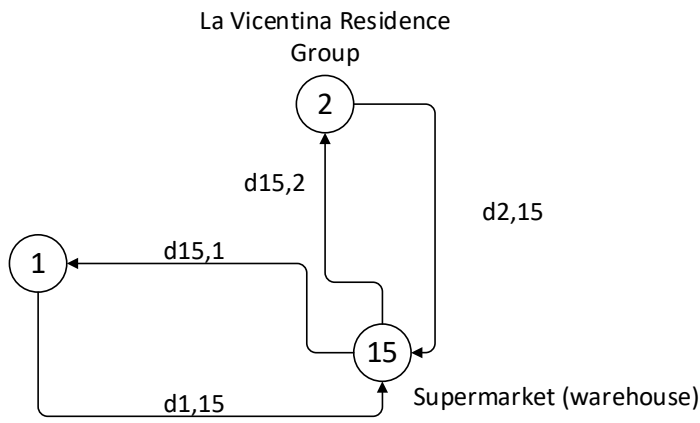

Initial route: route distance $=\mathrm{d} 15,1+\mathrm{d} 1,15+\mathrm{d} 15,2+\mathrm{d} 2,15$

Figure 3: the maximum distance route

Initially, with the help of a single vehicle, by simulating covering each stop and immediately returning to the supermarket, identified as number 15 , the route to be covered would result in the maximum distance experienced for the delivery of supplies, as is represented in Figure 3.
Nevertheless, when considering the saving of minimizing the distance that must be covered, the vehicle can combine a route or many routes, which would be found by algebraically subtracting the initial distance with the proposal represented in Figure 4:

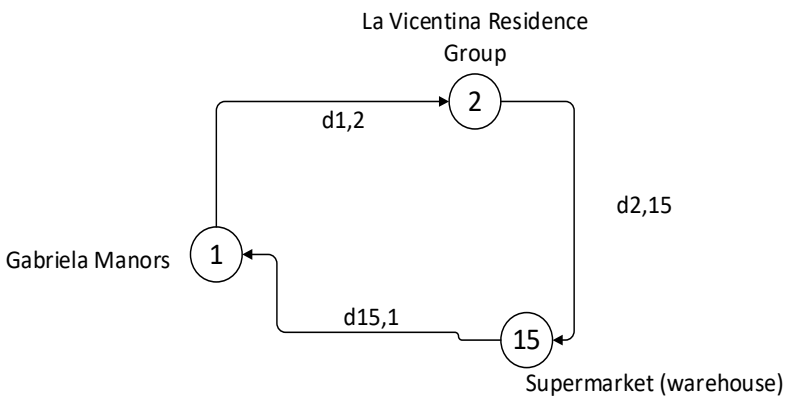

Combination of two stops $=\mathrm{d} 15,1+\mathrm{d} 1,2+\mathrm{d} 2,15$

By carrying out the algebraic operation of the operations previously defined in Figures 2 and 3, a savings value of $Z=d 15.1$ $+\mathrm{d} 2.15-\mathrm{d} 1.2$ would be obtained. This calculation is performed for all pairs of stops. The pair of stops with the highest savings value is selected for the respective combination.

This process is a continuous combination because, to combine single stops as in the previous case, the process can add another stop on a route that already contains multiple stops. For example, if point 7 were inserted between stops 1 and 2 where those points are on the same route, the value to be saved would be expressed as follows: $\mathrm{Z}=\mathrm{d} 15.7+\mathrm{d} 7.15+\mathrm{d} 1.2-\mathrm{d} 1.7-\mathrm{d} 2.7$. On the other hand, if stop seven were inserted after the last stop, point 2, the value of the route savings would be: $Z=d 2,15-d 2,7+d 15,7$. By contrast, if stop 7 were inserted before stop 1 , the value of the savings would be: $Z=d 7,15-d 7,1+d 1,15$. These savings calculations are repeated as progress is made in solving the problem. With this procedure, the highest savings value identifies the stop that should be considered for inclusion in a route.

If a particular stop, due to some circumstance or constraint, cannot be included, such as the route being excessively long or the capacity of the sole vehicle being exceeded, the stop with the next highest savings value is considered for inclusion; in the same way, this process would be repeated until all points or stops have been considered. This argument is supported due the strength of the method is the ability to simultaneously assign a stop to a specific route and place it in an area in the sequence of the route. In such circumstances, before accepting a stop on a route, the route must be provided with the new stop [5].

Therefore, the use of the only available vehicle by the supermarket must be programmed to send all orders for the week according to the schedule issued by government-controlled entities (06h00-13h00). Such orders can only be complied with by having only one departure in the morning and returning after all deliveries have been made. It is important to note that the dispatchers will be fed before and/or after the delivery of all the provision requests, considering that there is no constraint on this 
issue. The average driving speed is $50 \mathrm{~km} / \mathrm{h}$, in compliance with the maximum speed limit allowed within the city of Quito. Additionally, the calculation of the costs related to the dispatches - based on the salaries or wages of the staff that make the deliveries, the budget for the purchase of supplies and provisions to be delivered, fuel consumption, and car maintenance costs equates to an economic value of USD 5.50 per kilometer driven.

The model is posed in the software Logware Version 5.0 for Windows, which is formed by a collection of useful programs to analyze a wide variety of issues related to the management of logistic supply chains. The software has a module named "Route" that allows the user to determine the shortest route in a route network and to input multiple constraints based on the designed model.

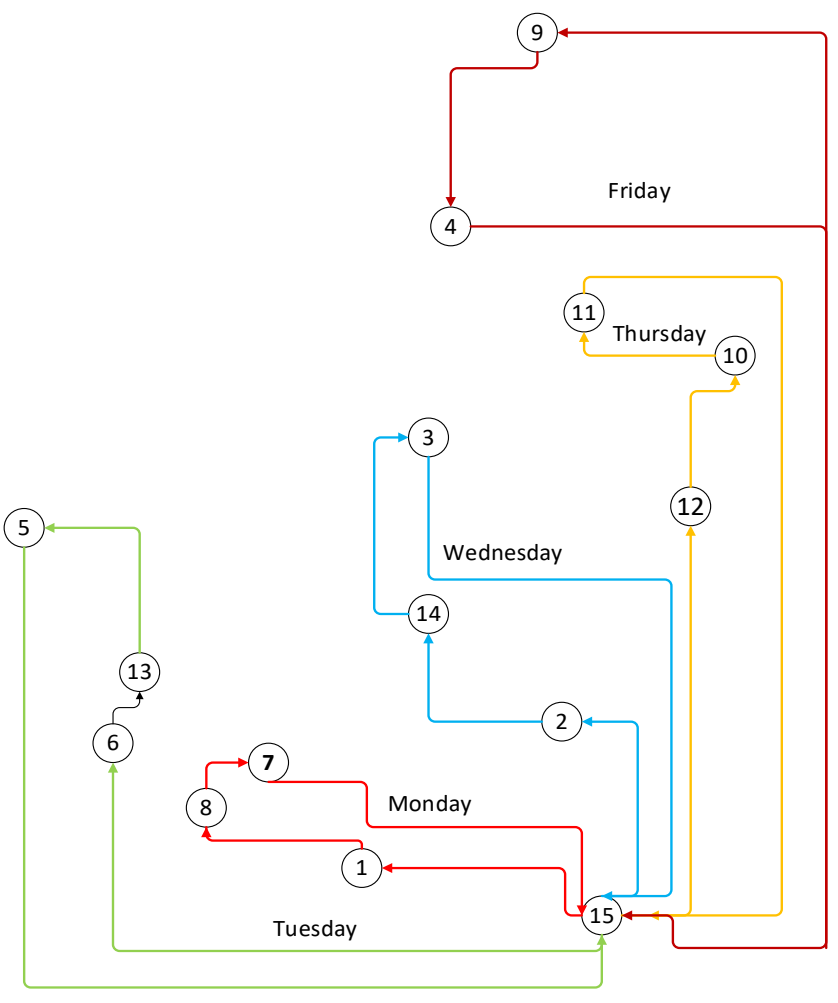

Figure 5: delivery provision routes

When these data were input into this software, and after several ride simulations, the feasible sequences to be implemented were found according to the details in Table 1.

When carrying out the respective work in Logware through the use of the "Route" software which allows the user to consider several additional constraints within savings assessment, enter the respective data, and execute route simulations the feasible sequences to be implemented were found, and are detailed in Table 1.

According to the data found and the determined economic value based on kilometers driven, the weekly cost for home delivery of provisions is USD 206.30. The graphical representation of the routes is illustrated in Figure 5.
Table 1: Optimal Routes to deliver provisions

\begin{tabular}{|c|c|c|c|c|c|c|c|}
\hline Route & Sequence & $\begin{array}{l}\text { Start } \\
\text { Time }\end{array}$ & $\begin{array}{l}\text { End } \\
\text { Time }\end{array}$ & $\begin{array}{c}\text { Route } \\
\text { Distan } \\
\text { ce } \\
(\mathbf{k m} .)\end{array}$ & $\begin{array}{c}\text { Route } \\
\text { Time } \\
\text { (hour } \\
\text { s) }\end{array}$ & $\begin{array}{c}\text { Deliver } \\
\text { y } \\
\text { Weight } \\
\text { (pound } \\
\text { s) }\end{array}$ & $\begin{array}{c}\text { Truck } \\
\text { size } \\
\text { (pound } \\
\text { s) }\end{array}$ \\
\hline Monday & $15,1,8,7,15$ & $\begin{array}{c}08: 0 \\
0\end{array}$ & $\begin{array}{c}11: 0 \\
0\end{array}$ & 6.32 & 3:00 & 750 & 1000 \\
\hline Tuesday & $15,6,13,5,15$ & $\begin{array}{c}08: 0 \\
0\end{array}$ & $\begin{array}{c}11: 3 \\
0\end{array}$ & 7.55 & $3: 30$ & 775 & 1000 \\
\hline $\begin{array}{c}\text { Wednesd } \\
\text { ay }\end{array}$ & $15,2,14,3,15$ & $\begin{array}{c}08: 0 \\
0\end{array}$ & $\begin{array}{c}11: 3 \\
0\end{array}$ & 6.83 & $3: 30$ & 790 & 1000 \\
\hline Thursday & $\begin{array}{c}15,12,10,11 \\
15\end{array}$ & $\begin{array}{c}08: 0 \\
0\end{array}$ & $\begin{array}{c}12: 3 \\
0\end{array}$ & 8.05 & $4: 30$ & 900 & 1000 \\
\hline Friday & $15,9,4,15$ & $\begin{array}{c}08: 0 \\
0\end{array}$ & $\begin{array}{c}12: 0 \\
0\end{array}$ & 8.76 & 4:00 & 810 & 1000 \\
\hline \multicolumn{4}{|c|}{ TOTAL } & 37.51 & 17.9 & 4,025 & \\
\hline
\end{tabular}

Source: Logware for Windows

\section{Conclusion}

The result achieved with this study provides an opportunity for a small supermarket to be able to continue with its work by delivering provisions at home in its direct area of influence while covering the largest number of customers through direct delivery in residential complexes. The model reflects the optimal weekly routes that the supermarket under study must use in order to comply with its customer's orders and thereby achieve significant savings in time and related costs.

This model was developed using the "savings method" logistics methodology through the Route module of the software program Logware, which facilitated running various simulations of routes that could potentially be applied. This software allows the user to find the shortest driven route in a route network, while making it possible to cover those distances at lower costs than empirical methods. The ideal route found shows that the transport of provisions can be performed weekly by covering a total distance of 37.51 kilometers at a cost of USD 206.30.

The results achieved enabled the supermarket to continue working in compliance with the requirements of the state control authorities of Ecuador, while also allowing a certain number of collaborators to keep their jobs and continue working during a difficult time for labor and economy. The formulation of the logistics model designed by using the savings method made it possible to form a model that has a sequential distribution of daily routes, thus facilitating the identification of additional constraints that could be used in the future to determine certain possible events that may be studied. It is important to mention that the model proposed for the supply business can be replicated by similar businesses, or by commercial establishments that want to make home deliveries while optimizing time and money.

The future work to perform is the determination and allocation of routes to new customers, considering especially that the global health problem will not be easily solvable in the short term, and that this model will allow the supermarket to increase its number of customers.

\section{References}

[1] O. Hernández, A. Jarrinson, F. Jiménez, T. Aguilar, "Suppliers and management models in the supply chain: Manufacturing SMEs of Aguascalientes", Acounting and administrative sciences, 7(1), 21-28, 2017.

[2] S. Rave, D. Arias, J. Garcia, " Proposal of a logistic model to reduce costs of 
the painting sub-process in furniture Bovel Ltda", Scientia Et Technica, 20(3), 240-246, 2015.

[3] Presidency of the Republic of Ecuador, "Decree Number 1052", 5 May 2020.Available:https://www.telecomunicaciones.gob.ec/wpcontent/uploads /2020/07/Decreto_Ejecutivo_No._1052_20200415200635.pdf

[4] E, Valentina, O. Galvis, D. López, J. Mock-Kow, I. Zapata, C. Vidal, "Logistics management in the provision of home care services in Valle del Cauca: characterization and diagnosis", Management studies, 30(133), 441450, 2014, doi:org/10.1016/j.estger.2014.06.004

[5] R. Ballou, Logistics. Supply chain management. Pearson, 2004.

[6] R. Jacobs, R. Chase, Operation Administration. Production and supply chain. Mc Graw Hill Education, 2019.

[7] Group Ibertransit Excellence Moves the World, "The logistics sector already represents $8 \%$ of the GDP sector", 15 September, 2019. Available: https://www.ibertransit.com/sector-logistico-8-pib

[8] Milenio 2020, "Logistics costs in Mexico", 2 September 2019. Available: https://www.milenio.com/opinion/varios-autores/emprendiendo-consentido-humano/costos-de-la-logistica-en-mexico.

[9] Inter-American Development Bank, "Regional Logistics Observatory. Logistics Costs", 20 July 2016. Available: http://logisticsportal.iadb.org/

[10] Municipality of the Metropolitan District of Quito, "Economic and productive situation of the DMQ". 6 November 2017. Available: http://gobiernoabierto.quito.gob.ec/wpcontent/uploads/documentos/pdf/dia gnosticoeconomico.pdf.

[11] Development Bank of Latin America, "Logistics roadmap in Ecuador will improve national competitiveness". 15 November 2019. Available: https://www.caf.com/es/actualidad/noticias/2019/11/hoja-de-ruta-logisticaen-ecuador-permitira-mejorar-la-competitividad-nacional/

[12] B, Hurtado, J. Robles, J. Preciado, N. Banuelos, "Transportation logistics and local development in Sonoran table grape export organizations", Social studies, 28(51), 2-25, 2018, doi:org/10.24836/es.v28i51.563

[13] M. Arango, C. Gómez, C. Serna, "Logistic models applied in the urban distribution of goods". EIA Magazine, 14(28),. 57-76, 2017, doi:org/10.24050/reia.v14i28.1055

[14] F. Duhamel, J. Duran, "Degrees of customization of logistics services: service priorities and performance". Nova Scientia, 7(13), 286-313, 2014.

[15] O. Gil, "Logistics: key to the global competitiveness of small and mediumsized companies in the state of Jalisco in Mexico". Paakat: Magazine of Technology and Society, 6(11), 22-44, 2016.

[16] P. Cano, F. Orue, J. Martinez, J. Mayett, G. López, "Logistics management model for small and medium-sized companies in Mexico", Acounting and administration, 60(1), 181-203, 2015.

[17] K. Salas-Navarro, J. Meza, T. Obredor, N. Mercado, "Evaluation of the supply chain to improve competitiveness and productivity in the metalworking sector in Barranquilla, Colombia", Technological information, 30(2), 25-32, 2019, doi:org/10.4067/S0718-07642019000200025

[18] J. Ruiz, M. González, L. Carménate, "Reverse logistics as a differentiation strategy for dynamic markets. Machala-Ecuador". Innova Research Journal 5(2), 140-156, 2020, doi:org/10.33890/innova.v5.n2.2020.1291

[19] F. Jaramillo, G. Granja, V. Del Pozo, "The logistics processes of textile and clothing companies: case of the textile company hilandería unida s.a .Guayaquil-Ecuador". In 2018 ECOTEC Society remainds and perspectives congress (ECOTEC), 55-62, 2018.

[20] J. Guamanquispe, M. Mancheno, D. Altamirano, S. Chaluisa, "A growing approach to the development of integral logistics. Ambato-Ecuador", Constructivism Web, 4(1), 116-134, 2019, doi:org/10.23857/pc.v4i1.876.

[21] J. Chicaiza, F. Sandaya, "Research in logistics and transportation: comparison between the countries of the Andean region; challenges and opportunities for its development in Ecuador", in 2015 ESPE Science and technology congress (ESPE), 275-280, 2015, doi.org/10.24133/cctespe.v10i1.60

[22] J. Orjuela, O. Diaz, A. González, "Characterization of logistics in the supply chain for cosmetics and personal care products", Scientific Magazine, 1(28), 81-96, 2017, doi: 10.14483/udistrital.jour.RC.2016.28.a7

[23] J. Silva, "Supply chain management: a review from logistics and the environment". Sciencie and engineering, 11(22), 51-59, 2017.

[24] D. Calero, J. Gamboa, M. Mancheno, "Logistics organization, competitive diagnosis in commercial warehouses in zone 3 of Ecuador", POCAIP, 5(17), 158-181, 2020, doi:org/10.23857/fipcaec.v5i5.190.

[25] World Health Organization (WHO), "Naming the coronavirus disease (COVID-19) and the virus that causes it". 5 May 2020. Available: https://www.who.int/emergencies/diseases/novel-coronavirus 2019/technical-guidance/naming-the-coronavirus-disease-(covid-2019)and-the-virus-that-causes-it

[26] J. Ascencio, R. Bustos, J. Jiménez, J. Balbuena, A. Zamora, “Automatic www.astesj.com
Wizard for design of distribution routes", Technical Publication, 14(1), 2-25, 2018.

[27] R. Álvarez, Proposal for resolution of the vehicle routing problem in the logistics operator Operar S.A., for transport and distribution of dry food products of the group Nutresa S.A", 12(2), 6-41, 2017.

[28] P. Cano, "Vehicle Routing Problem VRP", in 2020 UPAEP. Operations Research (UPAEP), 1-7, 2020.

[29] R. Rodríguez, "Interview with Tom Frieden", 7 May 2020. Available: https://www.elconfidencial.com/tecnologia/ciencia/2020-0507/coronavirusdiez-verdades-tom-frieden-experto-epidemiologico-eeuu_2583939/ 